gether 932 of these plants were utilised, and, similarly, half were provided with the dises and the rest left unprotected. From among the protected cauliflowers twenty-four were lost, as compared with 294 plants out of a similar number of unprotected ones. One of the advantages of this method over the more familiar use of paraffin and sand or soot is that a single application is sufficient, whereas the other remedies have to be reviewed periodically.

In addition to Mr. Wadsworth's experiments, I supplied three growers with the American discs, giving full instructions as to their manipulation. One grower at Chorlton (near Manchester), who was supplied with too discs, reported that no single case of root-maggot attack was noted where they were used. Another grower, at Prestwich (Cheshire), wrote to say that he had fifty cabbages with the discs on, and only two of them were attacked. Out of the fifty control plants most of them were infested. The third observer (at Nottingham) used roo discs, and reported that out of eighty-four protected cauliflowers only five were apparently attacked. and none were lost. From among twenty unprotected plants only twelve survived.

It is remarkable that a simple and effective measure should have attracted so little attention in this country or elsewhere in Europe. It appears to have been overlooked that its value has frequently been demonstrated in Canada and the United States, I may add that we hope to be able to have a supply of tarred felt paper discs available for use in this country during the forthcoming spring, when every effort will be needed to conserve the food supply of the nation.

A. D. Imms.

Department of Agricultural Entomology, Manchester University.

The Decimal System and Summer Time in France.

THE frequent references to the necessity of introducing the decimal system which one reads in the public Press at present suggest some considerations which an experience of more than two years with the B.E.F. has confirmed. It is surprising with what facility the average soldier becomes accustomed to French money. Everything out here is bought and paid for on the decimal system. The men and officers receive their pay in French money. I have seen bills made out and paid by officers' orderlies which show they are quite at home in the French system. It is, of course, perfectly evident that the time gained in schools and colleges, if we were to replace many confusing weights and measures now in use by the decimal system, would be of great importance. Here in France half a kilo is called a pound; a sou is called a halfpenny. There would be no need for us to change familiar names if we are lucky enough to adopt the decimal system. It may be said that everybody out here has. become familiar with decimal money, weights, and lengths, and knows roughly the ratios between them and corresponding British measure. The present opportunity is one which ought not to be missed. The stern teacher-war-has taught us to give up so many of our out-of-date ways that the imposition of the decimal system would soon be an accomplished fact if our rulers would only listen to those who really know.

This naturally suggests some facts connected with the introduction of "summer time." Whatever advantages that measure may have had from the point of view of those living in large towns, and of those whose time is their own (and they are many), it must certainly be confessed that in the case of the farming class in France it has been a complete failure. In fact, it exists only in name. I have NO. 2466, VOL. 98] spoken with the farmers on the subject, and they all assured me that it was no good to them. The houtest time of the day is about $2.0 \mathrm{p} . \mathrm{m}$. Now, according to the summertime programme, the greatest heat corresponds to 3.0 p.m. If, then, the farmer dines at noon (which is universal) he must do his afternoon's work during the hottest hours of the day. As a matter of fact, the farmers make no change in their habits. Many of them do not change their clocks, and dine at r.o p.m. according to summer time. But see the result. The schools must follow the legal time, the children get home for their dinners an hour before the family has begun to dine, with the result that there is the greatest confusion in a household, especially where the mother has to work in the fields. Again, there is the disadvantage that those occupied with cattle, as in Ireland, have an extra hour of darkness for their most important industry.

The case of Ireland is especially hard. Since the abolition of "Irish time" there is already an extra half-hour of darkness in the mornings; if the clock in Ireland is put back another hour it will mean that in many places the extra darkness in the mornings will be more than an hour and a half. It seems to the writer that the greatest care should be taken before the present system of summer time is made perpetual. It would be much better and much more scientific and more straightforward if the opening hour of all public offices, etc., was advanced an hour, and their time of closing treated in the same way. In conclusion, I may add, as a proof of the confusion which exists in some parts of France, the list of services in the parish church had to be written in two, columns, the legal time being in ordinary figures, the summer time in Roman numerals. C. F.

France, January 22.

\section{Meldola Memoriál}

A MOVEMENT has recently been initiated to institute, at the Finsbury Technical College, a reference library of chemical books in memory of the late Prof. Raphael Meldolla, F.R.S., who formerly presided over this school of applied chemistry.

We beg to bring under your notice this appeal, which has met with generous support from many former students of Prof. Meldola, because we believe that his other friends outside the college dircle would welcome the opportunity of helping to make this memorial a fitting tribute to a strenuous life spent in the pursuit of science in many varied aspects.

The proposed chemical library would be of the utmost utility to past and present students of this college, and, in all probability, suitable arrangements could be made to render it available to the scientific public for purposes of special neferences. It would be situated in a part of London where such facilities are at present non-existent.

Donations towards the memorial fund would be greatly appreciated by the undersigned committee and by all who have at heart the development of applied chemistry, a branch of soience which the war has shown to be of national importance.
J. L. BAKER (Hon. Treasurer).
J. H. Coste.
M. O. Forster.
H. F. KNIGHT.
G. T. Morgan.
F. W. Streatfeild
C. H. Butcher

Finsbury Technical College, Leonard Street, City Road, London, E.C. 